\title{
Papers
}

\section{Clinical efficacy of antiretroviral combination therapy based on protease inhibitors or non-nucleoside analogue reverse transcriptase inhibitors: indirect comparison of controlled trials}

\author{
Yazdan Yazdanpanah, Daouda Sissoko, Matthias Egger, Yves Mouton, Marcel Zwahlen, Geneviève Chêne
}

\begin{abstract}
Objective To compare the clinical efficacy of triple antiretroviral regimens based on protease inhibitors and non-nucleoside analogue reverse transcriptase inhibitors (NNRTIs) in adults positive for antibodies to HIV-1.

Design Systematic review and meta-analysis using indirect comparisons of clinical trials comparing three drug regimens based on two nucleoside reverse transcriptase inhibitors (NRTIs) and either a protease inhibitor or an NNRTI with two drug regimens (two NRTIs). Participants had no previous exposure to protease inhibitors or NNRTIs.

Data sources Medline, the Cochrane controlled trials register, Aidstrials, Aidsdrugs, conference proceedings, and trial registers.

Main outcome measure Progression to AIDS or death. Results 14 trials, totalling 6785 patients, were identified. Most patients had been exposed to an NRTI and had advanced immunodeficiency at baseline; 1096 progressed to AIDS or died. Seven trials assessed protease inhibitors based triple regimens and seven assessed NNRTI based triple regimens (nevirapine or delavirdine). Triple therapy was more effective than dual therapy. The effect was pronounced for protease inhibitor based regimens (odds ratio $0.49,95 \%$ confidence interval 0.41 to 0.58 ) but non-significant for NNRTI based regimens $(0.90,0.71$ to 1.15$)$. Indirect comparison of the two regimens gave an odds ratio of 0.54 (0.49 to 0.73 ) in favour of protease inhibitor based treatments. Increases in CD4 cell counts were smaller and suppression of viral replication less with NNRTI based regimens.

Conclusions Indirect evidence shows that protease inhibitor based triple regimens are superior to regimens based on the NNRTIs nevirapine and delavirdine in patients with advanced immunodeficiency who have been exposed to NRTIs. Large trials with clinical end points are required.
\end{abstract}

\section{Introduction}

The introduction in industrialised countries of highly active antiretroviral therapy-a combination of three drugs including either a protease inhibitor or a non-nucleoside analogue reverse transcriptase inhibitor (NNRTI) and two nucleoside analogue reverse transcriptase inhibitors (NRTIs)-led to a dramatic decline in morbidity and mortality among patients infected with HIV- $1 .^{1-3}$ Many different combinations of highly active antiretroviral therapy regimens are available, some of which differ in toxicity, adverse events, their ability to suppress viral repli- cation, the development of viral resistance, and patient

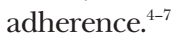

Randomised clinical trials are accepted as the most powerful tool for assessing the effectiveness of medical interventions, yet no trials have compared the clinical effectiveness of protease inhibitor based and NNRTI based combination therapies. Thus it is unclear whether there are relevant differences between the regimens in prevention of clinical progression to AIDS or death. In trials comparing highly active antiretroviral therapy regimens the low rate of disease progression made it impractical to use clinical events as primary end points. A meta-analysis of 16 randomised trials showed that treatments resulting in similar changes in HIV-1 RNA or CD4 cell counts were associated with widely varying clinical outcomes. ${ }^{8}$ Trials exclusively reporting surrogate endpoint data therefore have to be interpreted with caution. $^{9}$

In the absence of trials comparing two treatments, indirect comparisons have been advocated. ${ }^{10}$ We performed indirect comparisons between triple regimens based on protease inhibitors and NNRTIs by using clinical and surrogate endpoint data from randomised controlled trials comparing triple regimens with dual regimens.

\section{Methods}

Using Cochrane methods we searched Medline, the Cochrane controlled trials register, Aidstrials, and Aidsdrugs for randomised clinical trials of antiretroviral therapy in patients infected with HIV-1 published from January 1994 to December $2000 .{ }^{11}$ The search ended in 2000 because after this date comparisons between triple and dual regimens were not performed. We used the keywords "HIV infections", "anti-HIV agents", "antiretroviral therapy", and "adults" and MeSH terms for individual drug names. The results were combined with those from standard searches for randomised controlled trials. ${ }^{11} \mathrm{We}$ also hand searched reference lists, reviews, and abstracts from major conferences and consulted the French Arcat Sida register, the European database on AIDS and HIV infection, and the database of the US Community Programs for Clinical Research on AIDS. Finally, we contacted experts and pharmaceutical companies. We screened the titles and abstracts of articles and obtained copies of potentially eligible articles.

Inclusion criteria, data abstraction, and outcomes

We included randomised controlled studies published in any language if they reported on clinical end points and enrolled patients who were HIV-1 positive, aged 16 years or older, and 
had not received protease inhibitors or NNRTIs. We were interested in triple antiretroviral therapy compared with dual therapy based on recommended antiretroviral agents. ${ }^{12}{ }^{13}$ Dual therapy was defined as a combination of two NRTIs and triple therapy as two NRTIs combined with a protease inhibitor or an NNRTI.

DS and YY independently extracted the data using a structured questionnaire. Discrepancies were resolved by discussion with GC. We assessed outcomes at the end of the follow up period or at the time point before a switch from dual therapy to triple therapy was allowed by the study protocol. The primary outcome was progression to a new AIDS defining disease or death. ${ }^{14}$ Additional outcomes included the CD4 cell count, plasma HIV-1 RNA concentration, and the proportion of patients reaching plasma HIV-1 RNA concentrations of less than 500 copies $/ \mathrm{ml}$ at the end of follow up. In some instances we calculated standard deviations of means of CD4 cell counts and plasma HIV-1 RNA concentrations from 95\% confidence intervals or estimated them from interquartile ranges or from error bars displayed in graphs. We assessed the methodological quality of trials on the basis of adequacy of concealment of patients' allocation to treatment group and blinding to placebo. ${ }^{15}$

\section{Statistical analysis}

Data on clinical progression and suppression of viral replication were based on intention to treat analyses, which included all patients irrespective of adherence to treatments or follow up. We calculated odds ratios with $95 \%$ confidence intervals, comparing the probability of clinical progression and the probability of reaching HIV-1 RNA concentrations below 500 copies $/ \mathrm{ml}$ between patients receiving triple and dual antiretroviral therapy. To estimate changes in CD4 cell counts and in viral load from baseline, we extracted data on CD4 cells and viral load at the latest follow up time. We excluded follow up visits with less than half the total number of patients. Positive differences in CD4 cell counts and negative differences in viral load indicated superior treatment responses.

We used random effects models to combine results on the odds ratio or weighted mean difference scales. ${ }^{16}$ The degree of between trial heterogeneity (measured by the additive between trial variance, $\tau^{2}$ ) was estimated using an iterative restricted maximum likelihood method. ${ }^{17}$ Publication bias was assessed by funnel plot. ${ }^{18}$ Standard tests of homogeneity of odds ratios and weighted mean differences were also calculated. ${ }^{16}$ Crude and adjusted indirect comparisons were performed by fitting random effects meta-regression models. ${ }^{17}{ }^{19}$ Variables entered in the model were type of regimens compared (protease inhibitor based or NNRTI based triple regimens, type of NRTI backbone); other study characteristics (length of follow up, year of publication, full publication or abstract only); and characteristics of study populations at baseline (median age, whether patients were NRTI naive, proportion of patients with AIDS, average CD4 cell count, average viral load). We also included two variables relating to the quality of trials (whether or not an adequate method of allocation concealment was described and whether or not placebos were used). Finally we examined whether the censoring strategy affected results. In some trials, follow up was censored at the time of virological failure, which could bias comparisons of clinical end points. All analyses were performed in Stata 8.0

\section{Results}

Of 367 citations identified, we examined 54 articles in detail and found 12 trials that met our inclusion criteria. Two unpublished trials were identified from conference proceedings (fig 1). The 14

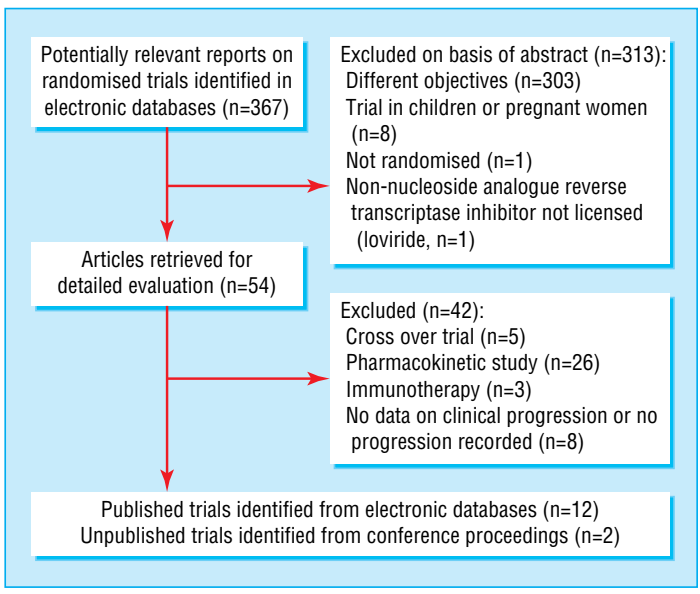

Fig 1 Identification of relevant trials

trials totalled 6785 patients (table 1 )..$^{20-33}$ Over $80 \%$ of participants were men, median age ranging from 31 to 41 years. Some trials exclusively enrolled patients with a history of AIDS and others enrolled patients free of AIDS, but most enrolled patients with advanced immunodeficiency. The median CD4 cell count at baseline ranged from 19 to 651 cells $/ \mu \mathrm{l}$, and the median HIV RNA ranged from 4.4 to $6.4 \log _{10}$ copies/ml. Only three trials enrolled patients naive to NRTIs. Follow up ranged from 24 to 80 weeks. Of the 14 triple combinations, seven were based on a protease inhibitor and seven on an NNRTI. Seven trials used protease inhibitors: indinavir (three trials) and saquinavir and ritonavir (two each). Four trials used the NNRTI nevirapine and three the NNRTI delavirdine. The most common NRTI dual therapy regimen was zidovudine and didanosine (five trials) followed by zidovudine and lamivudine (four). Nine trials described adequate concealment of allocation and 12 used placebos to blind patients and caregivers.

\section{Clinical progression}

Clinical progression occurred in 445 of 3392 patients (13.1\%) receiving triple therapy and 651 of 3393 (19.2\%) patients receiving dual therapy (fig 2): combined odds ratio 0.65 (95\% CI 0.52 to 0.81$)$. Heterogeneity was evident between trials, with odds ratios ranging from 0.32 to $1.31\left(\tau^{2}=0.073\right.$, test of heterogeneity $\mathrm{P}=0.090)$.

In univariate meta-regression analysis, protease inhibitor based triple regimens showed larger treatment effects than those based on NNRTIs $(\mathrm{P}<0.0001)$, triple regimens including didanosine showed smaller treatment effects than those that did not include didanosine $(\mathrm{P}<0.0001)$, and trials that enrolled a larger proportion of patients with AIDS tended to show larger differences in treatment effects between triple and dual regimens $(\mathrm{P}=0.067)$. These variables were responsible for the between trial heterogeneity. We found little evidence for an association with other variables entered in the model, including length of follow up $(\mathrm{P}=0.76)$, year of publication of the trial $(\mathrm{P}=0.22)$, publication in full or as abstract only $(\mathrm{P}=0.34)$, median age of study populations at baseline $(\mathrm{P}=0.98)$, whether patients were NRTI naive or not $(\mathrm{P}=0.75)$, and $\mathrm{CD} 4$ cell count $(\mathrm{P}=0.53)$ and viral load $(\mathrm{P}=0.37)$ at baseline. Finally, there was little evidence that the censoring strategy (follow up censored at virological failure yes or no, $\mathrm{P}=0.46$ ) or the quality of trials influenced results (adequate concealment of allocation yes or no, $\mathrm{P}=0.91$; use of placebo yes or no, $\mathrm{P}=0.63$ ), and little evidence of funnel plot asymmetry $(\mathrm{P}=0.27)$. 
Table 1 Characteristics of 14 randomised controlled trials comparing protease inhibitor based triple therapy and non-nucleoside analogue reverse transcriptase inhibitor (NNRTI) based triple regimens with dual therapy

\begin{tabular}{|c|c|c|c|c|c|c|c|c|}
\hline Trials & $\begin{array}{l}\text { No of } \\
\text { patients }\end{array}$ & $\begin{array}{l}\text { Median age } \\
\text { (years) }\end{array}$ & No $(\%)$ male & $\begin{array}{c}\text { No (\%) } \\
\text { with AIDS }\end{array}$ & $\begin{array}{l}\text { Median CD4 cell } \\
\text { counts } / \mu 1^{*}\end{array}$ & $\begin{array}{c}\text { Median HIV RNA } \\
\text { concentration }(\log 10 \\
\text { copies } / \mathrm{ml})^{*}\end{array}$ & $\begin{array}{c}\text { Follow up } \\
\text { (weeks) }\end{array}$ & Drug comparison \\
\hline \multicolumn{9}{|l|}{$\begin{array}{l}\text { Protease inhibitor based } \\
\text { regimen: }\end{array}$} \\
\hline $\begin{array}{l}\text { AIDS Clinical Trials Group } \\
229,1996^{24}\end{array}$ & 198 & 38 & $183(92)$ & $23(11)$ & 158 & 4.8 & $36-56$ & $\begin{array}{l}\text { Saquinavir, zidovudine, and } \\
\text { zalcitabine } v \text { zidovudine and } \\
\text { zalcitabine }\end{array}$ \\
\hline $\begin{array}{l}\text { AIDS Clinical Trials Group } \\
320,1997^{21}\end{array}$ & 1156 & 39 & NR & $1156(100)$ & 87 & 5.0 & 38 & $\begin{array}{l}\text { Indinavir, zidovudine, and } \\
\text { lamivudine } v \text { zidovudine and } \\
\text { lamivudine }\end{array}$ \\
\hline Merck 035, $1997^{20}$ & 66 & 41 & $58(88)$ & 8 (13) & 139 & 4.6 & 52 & $\begin{array}{l}\text { Indinavir, zidovudine, and } \\
\text { lamivudine } v \text { zidovudine and } \\
\text { lamivudine }\end{array}$ \\
\hline RTV Study Group, $1998^{22}$ & 1090 & 38 & 999 (92) & $1090(100)$ & 20 & 5.4 & 26 & $\begin{array}{c}\text { Ritonavir and two NRTIs } v \text { two } \\
\text { NRTIs }\end{array}$ \\
\hline Merck 039, $1999^{27}$ & 213 & 40 & $186(87)$ & $119(56)$ & 19 & 4.8 & 24 & $\begin{array}{l}\text { Indinavir, zidovudine, and } \\
\text { lamivudine } v \text { zidovudine and } \\
\text { lamivudine }\end{array}$ \\
\hline Spanish Earth-1, $1999^{28}$ & $66 \dagger$ & 31 & $45(68)$ & 0 & 651 & 4.6 & 52 & $\begin{array}{l}\text { Ritonavir, stavudine, and } \\
\text { lamivudine } v \text { stavudine and } \\
\text { didanosine }\end{array}$ \\
\hline PISCES, $2000^{31}$ & 1897 & 34 & $1576(83)$ & NR & 210 & 5.1 & 80 & $\begin{array}{l}\text { Saquinavir, zidovudine, and } \\
\text { zalcitabine } v \text { zidovudine and } \\
\text { zalcitabine }\end{array}$ \\
\hline \multicolumn{9}{|l|}{ NNRTI based regimen: } \\
\hline $\begin{array}{l}\text { AIDS Clinical Trials Group } \\
241,1996^{23}\end{array}$ & 398 & 38 & $318(80)$ & $66(17)$ & 137 & 6.4 & 48 & $\begin{array}{l}\text { Nevirapine, zidovudine, and } \\
\text { didanosine } v \text { zidovudine and } \\
\text { didanosine }\end{array}$ \\
\hline $\begin{array}{l}\text { AIDS Clinical Trials Group } \\
193 \mathrm{~A}, 1997^{25}\end{array}$ & 662 & 38 & $576(87)$ & $662(100)$ & 19 & 4.8 & 65 & $\begin{array}{l}\text { Nevirapine, zidovudine, and } \\
\text { didanosine } v \text { zidovudine and } \\
\text { didanosine }\end{array}$ \\
\hline Study 0021 Pt 2, $1998^{32}$ & 248 & NR & NR & NR & 358 & 4.4 & 52 & $\begin{array}{l}\text { Delavirdine, zidovudine, and } \\
\text { lamivudine } v \text { zidovudine and } \\
\text { lamivudine }\end{array}$ \\
\hline INCAS, $1998^{26}$ & $104 \dagger$ & 38 & $97(93)$ & 0 & 388 & 4.4 & 52 & $\begin{array}{l}\text { Nevirapine, zidovudine, and } \\
\text { didanosine } v \text { zidovudine and } \\
\text { didanosine }\end{array}$ \\
\hline ISS 047, $1999^{29}$ & $68 \dagger$ & 37 & $58(85)$ & $27 \quad(40)$ & 83 & 5.6 & 48 & $\begin{array}{l}\text { Nevirapine, zidovudine, and } \\
\text { didanosine } v \text { zidovudine and } \\
\text { didanosine }\end{array}$ \\
\hline $\begin{array}{l}\text { AIDS Clinical Trials Group } \\
261,1999^{30}\end{array}$ & 274 & 35 & $228(83)$ & NR & 289 & 4.4 & 48 & $\begin{array}{l}\text { Delavirdine, zidovudine, and } \\
\text { didanosine } v \text { zidovudine and } \\
\text { didanosine }\end{array}$ \\
\hline Study $13 C, 1999^{33}$ & 345 & 36 & $226(66)$ & $225(65)$ & 210 & 4.9 & 52 & $\begin{array}{c}\text { Delavirdine, zidovudine, and } \\
\text { one NRTI } v \text { zidovudine and one } \\
\text { NRTI }\end{array}$ \\
\hline
\end{tabular}

NR=not reported.

*Mean values used if median not available.

†Patients naive to nucleoside analogue reverse transcriptase inhibitors.

Figure 3 shows the results from direct comparisons of triple with dual regimens and from indirect comparisons between triple regimens. When triple regimens were compared with dual regimens the odds ratio for clinical progression was 0.49 (0.41 to $0.58)$ for a protease inhibitor regimen but 0.90 (0.71 to 1.15$)$ for an NNRTI regimen. The crude odds ratio from the indirect comparison was 0.54 (0.40 to 0.73 ). This changed little when adjusting for whether or not the regimen included didanosine, for the proportion of study participants with AIDS, or for both variables, although adjustments resulted in odds ratios with wide confidence intervals, which included 1 (fig 3). When trials were excluded that examined saquinavir hard gel, which is no longer used, or the NNRTI delavirdine, which is not widely used, the protease inhibitor based triple regimens continued to show larger treatment effects than the NNRTI based regimens $(0.54$, 0.37 to 0.77$)$.

\section{Differences in CD4 cell count and plasma HIV-1 RNA \\ concentration}

Eleven studies could be included in the analysis of CD4 cell counts. Compared with dual regimens, triple regimens led to a superior CD4 cell response (pooled difference in CD4 cell count, 40 cells $/ \mu \mathrm{l}, 95 \%$ CI 19 to 60 cells $/ \mu \mathrm{l}$; table 2 ). When we stratified the analysis according to type of triple regimen, those based on protease inhibitors showed a greater improvement in CD4 cell count: 49 cells $/ \mu \mathrm{l}$ compared with 18 cells/ $\mu \mathrm{l}$ with NNRTI based regimens. An indirect comparison showed an additional increase of $25 \mathrm{CD} 4$ cells $/ \mu \mathrm{l}$ ( -17 to 68 ) with protease inhibitor based regimens. Ten studies reported HIV-1 RNA concentrations at the end of follow up, and nine reported the proportion of patients with plasma HIV RNA concentrations $\leq 500$ copies $/ \mathrm{ml}$. Again, triple therapy was superior to dual therapy, resulting in an estimated additional reduction of HIV-1 RNA concentrations of $0.56 \log$ copies $/ \mathrm{ml}$ (0.92 to 0.19 reduction in log copies $/ \mathrm{ml}$ ). The odds ratio for achieving a viral load below 500 copies $/ \mathrm{ml}$ with triple compared with dual therapy was 9.6 (4.4 to 21.0). Protease inhibitor based triple regimens resulted in a more substantial reduction of HIV-1 RNA concentrations $(-0.79 \log$ copies $/ \mathrm{ml})$ than NNRTI based regimens $(-0.20 \log$ copies $/ \mathrm{ml})$, and a higher proportion of patients reached undetectable viral load with the protease inhibitor regimens (odds ratio 37.1) than with 


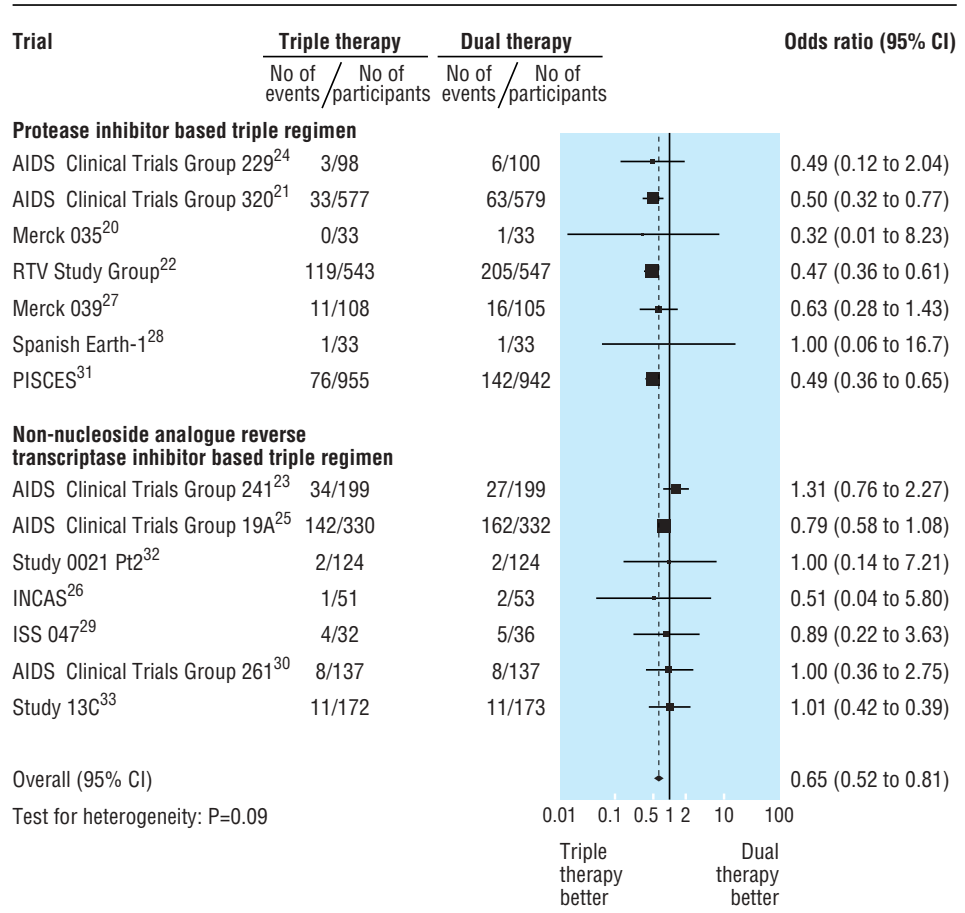

Fig 2 Meta-analysis of randomised controlled trials comparing effect of triple antiretroviral regimens with dual regimens on progression to AIDS or death, stratified by type of triple regimen

the NNRTI based regimens (4.1). The indirect comparison showed an additional reduction of HIV RNA concentration of $-0.59 \log$ copies $/ \mathrm{ml}$ with protease inhibitor regimens $(-1.32$ to $0.15)$. The odds ratio for reaching an undetectable viral load was 6.0 (2.2 to 16.6$)$

\section{Discussion}

Triple antiretroviral therapy is superior to dual therapy for preventing progression to AIDS or death in patients with advanced disease. Surprisingly, we found large variation between the results of the included trials. This was largely explained by the drug classes used in triple regimens: those containing protease inhibitors were clearly superior to dual regimens but this was not the case for triple regimens based on the NNRTIs nevirapine or delavirdine. Indirect comparisons indicated that the risk of clini- cal progression was reduced by $40 \%$ to $50 \%$ with protease inhibitor based regimens. In line with these findings, we found smaller increases in CD4 cell counts and less pronounced suppression of viral replication with the NNRTI based regimens.

\section{Strengths and limitations}

No data from direct randomised comparisons of the clinical efficacy of different triple antiretroviral regimens exist. Our systematic review is based on 6785 patients, 1096 of whom progressed to AIDS or died, from trials comparing triple regimens with dual regimens. This represents a large evidence base, suitable for indirect comparisons of the clinical effectiveness of the antiretroviral regimens. Such comparisons were appropriate because the trials were similar and of high methodological quality. All reports provided data that allowed analyses by intention to treat.

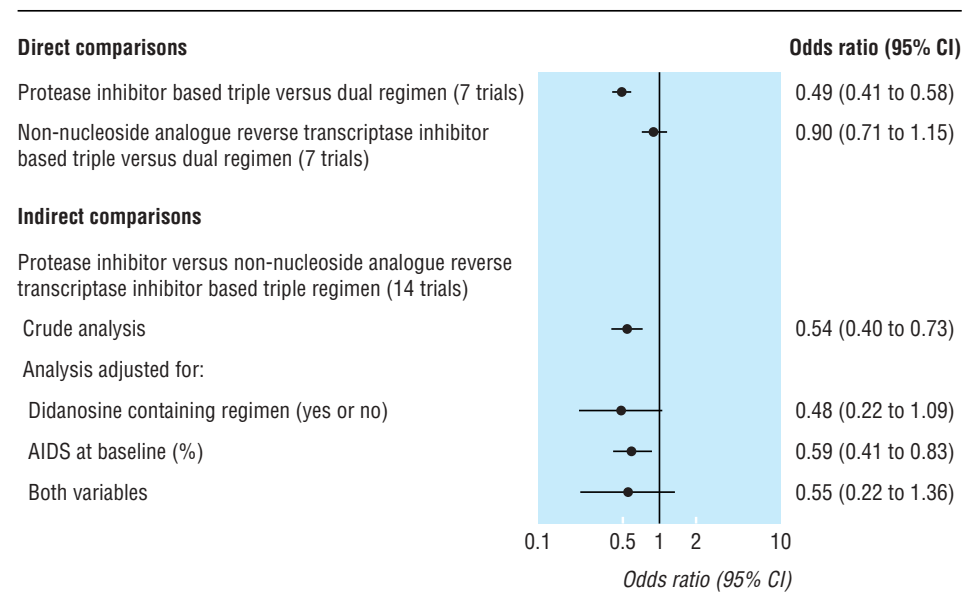

Fig 3 Comparisons from meta-analysis of randomised controlled trials comparing the effects of triple antiretroviral regimens with dual regimens on risk of progression to AIDS or death 
Table 2 Differences in CD4 cell counts and viral load at end of treatment with triple antiretroviral regimens or dual regimens, and probability of suppressing viral replication

\begin{tabular}{|c|c|c|c|c|c|c|c|c|c|}
\hline \multirow[b]{2}{*}{ Trials } & \multicolumn{3}{|c|}{ CD4 cell count $(\text { cells } / \mu / l)^{*}$} & \multicolumn{3}{|c|}{ Viral load $\left(\log _{10} \text { copies } / \mathrm{ml}\right)^{\star}$} & \multicolumn{3}{|c|}{ Viral load (<500 copies/ml) } \\
\hline & $\begin{array}{c}\text { Triple } \\
\text { therapy }\end{array}$ & Dual therapy & Difference $(95 \%$ Cl) & $\begin{array}{l}\text { Triple } \\
\text { therapy }\end{array}$ & $\begin{array}{c}\text { Dual } \\
\text { therapy }\end{array}$ & Difference $(95 \% \mathrm{Cl})$ & $\begin{array}{c}\text { Triple } \\
\text { therapyt }\end{array}$ & $\begin{array}{c}\text { Dual } \\
\text { therapyt }\end{array}$ & $\begin{array}{c}\text { Odds ratio }(95 \% \\
\text { CI) }\end{array}$ \\
\hline \multicolumn{10}{|c|}{ Protease inhibitor based regimens } \\
\hline \multicolumn{10}{|c|}{$\begin{array}{l}\text { AIDs Clinical Trials } \\
\text { Groups: }\end{array}$} \\
\hline 229 & 157 & 170 & $-13(-19$ to -7$)$ & 4.40 & 4.52 & $-0.12(-0.44$ to 0.20$)$ & NR & NR & - \\
\hline $320^{21}$ & 208 & 127 & 81 (53 to 109) & 2.90 & 4.00 & $-1.10(-1.55$ to -0.65$)$ & $42 / 93$ & $6 / 97$ & $12.5(5.0$ to 31.4$)$ \\
\hline Merck $035^{20}$ & 219 & 190 & 29 (-4 to 62$)$ & 2.87 & 3.81 & $-0.94(-1.24$ to -0.64$)$ & $28 / 33$ & $0 / 33$ & $\begin{array}{c}347 \\
(18.4 \text { to } 6500)\end{array}$ \\
\hline RTV Study Group 22 & 68 & 20 & 48 (44 to 52 ) & 4.80 & 5.70 & $-0.90(-1.12$ to -0.68$)$ & NR & NR & - \\
\hline Merck $039^{27}$ & 114 & 24 & 90 (77 to 103$)$ & 3.31 & 4.48 & $-1.17(-1.36$ to -0.98$)$ & $60 / 108$ & $0 / 105$ & $\begin{array}{c}263 \\
(15.9 \text { to } 4300)\end{array}$ \\
\hline Spanish Earth-1 ${ }^{28}$ & 901 & 808 & 93 (30 to 156) & 2.45 & 2.79 & $-0.34(-0.54$ to -0.14$)$ & $30 / 33$ & $11 / 33$ & $20.0(5.0$ to 80.3$)$ \\
\hline $\mathrm{PISCES}^{31}$ & 269 & 234 & 35 (24 to 46) & NR & NR & - & NR & NR & - \\
\hline Combined $\neq$ & - & - & $\begin{array}{c}49 \text { (18 to 80); } \\
P<0.0001\end{array}$ & - & - & $\begin{aligned}-0.76 & (-1.11 \text { to }-0.41) \\
& P<0.0001\end{aligned}$ & - & - & $\begin{array}{l}42 \begin{array}{l}(9.0 \text { to } 198) ; \\
P=0.026\end{array}\end{array}$ \\
\hline \multicolumn{10}{|c|}{ Non-nucleoside reverse transcriptase based regimens } \\
\hline \multicolumn{10}{|c|}{ AIDS Clinical Trials Group: } \\
\hline $241^{23}$ & 115 & 93 & 22 (3 to 41$)$ & 6.80 & 6.06 & $0.74(0.45$ to 1.03$)$ & NR & NR & - \\
\hline $193 A^{25}$ & 18 & 14 & $4(0.6$ to 7$)$ & 4.42 & 4.81 & $-0.39(-0.60$ to -0.18$)$ & NR & NR & - \\
\hline Study 0021 Pt $2^{32}$ & NR & NR & - & NR & NR & - & $25 / 124$ & $7 / 124$ & 4.2 (1.8 to 10.2$)$ \\
\hline INCAS $^{26}$ & 526 & 477 & 49 (-8 to 106$)$ & 1.94 & 3.37 & $-1.43(-2.30$ to -0.56$)$ & $20 / 51$ & $8 / 53$ & $3.6(1.4$ to 9.3$)$ \\
\hline ISS $047^{29}$ & NR & NR & - & NR & NR & - & $15 / 32$ & $3 / 36$ & 9.7 (2.5 to 38.2$)$ \\
\hline $\begin{array}{l}\text { AIDS Clinical Trials Group } \\
261^{30}\end{array}$ & 359 & 328 & 31 (-2 to 64$)$ & 3.74 & 3.78 & $-0.04(-0.42$ to 0.34$)$ & $13 / 61$ & $8 / 60$ & 1.8 (0.7 to 4.6$)$ \\
\hline Study $13 \mathrm{C}^{33}$ & NR & NR & - & $\mathrm{NR}$ & NR & - & $34 / 172$ & $7 / 173$ & 5.8 (2.5 to 13.6) \\
\hline Combined $\ddagger$ & - & - & $\begin{array}{c}18(0.1 \text { to } 35) ; \\
P=0.044\end{array}$ & - & - & $\begin{array}{c}-0.20 \quad(-0.89 \text { to } 0.50) ; \\
P<0.0001\end{array}$ & - & - & $\begin{array}{c}4.1 \text { (2.5 to } 6.7) ; \\
P=0.264\end{array}$ \\
\hline Indirect comparison & - & - & 25 (-17 to 68) & - & - & $-0.59(-1.32$ to 0.15$)$ & - & - & 6 (2.2 to 16.6$)$ \\
\hline
\end{tabular}

\section{NR=not reported.}

* Mean values used if median not available.

†Number of participants with viral load $<500$ copies/ml (total number of participants); 0.5 added for zero cell counts.

$\ddagger \mathrm{P}$ values from test of heterogeneity.

Our findings should, however, be interpreted with caution. Firstly, the finding of superior efficacy of protease inhibitor based regimens by indirect comparison is observational and therefore vulnerable to bias. Baseline characteristics of the participants were heterogeneous in both groups, with large variations in the proportion of patients with AIDS, the median CD4 cell count, and viral load. Furthermore, didanosine was more often used with NNRTIs than with protease inhibitors. When we adjusted for these differences in meta-regression models, the coefficients were not noticeably altered. We acknowledge that we could only adjust for information that was aggregated at the trial level. Individual patient data would have been preferable but were not available. Song et al recently showed that indirect comparisons adjusted at the aggregate level usually agree with direct comparisons..$^{10}$ Finally, the smaller gains in CD4 cell counts and less pronounced suppression of viral replication with NNRTI based regimens support the finding of higher progression rates.

Our results are limited to the regimens and patient populations of the included studies-for example, the NNRTI efavirenz was not included in the triple regimens. The trials involving efavirenz that we identified did not assess clinical end points and had to be excluded. Several observational cohort studies have shown efavirenz to be more efficacious than nevirapine. ${ }^{34-36}$ However, the recent $2 \mathrm{NN}$ trial, which directly compared these two drugs in antiretroviral naive patients showed that they did not differ in their virological efficacy. ${ }^{37}$ Furthermore, most of the patients enrolled in the trials in our metaanalysis used NRTIs. Thus, it is not possible to extrapolate these results to HIV-1 infected patients who have never used antiretroviral drugs, a population in whom NNRTI based regimens are widely used. It may be postulated that due to cross resistance, patients who have previously undergone prolonged therapy with NRTIs would be resistant to all drugs in the NRTI class. In this situation, a regimen containing one protease inhibitor and two NRTIs could be more effective than a regimen based on one NNRTI and two NRTIs because the genetic barrier to resistance is greater with protease inhibitors. ${ }^{38}$

\section{Results in context with other studies}

Three trials directly compared the virological and immunological response to protease inhibitor based and NNRTI based regimens. In one study, the authors compared regimens that combined two NRTIs with nelfinavir, efavirenz, or both, in patients who had failed to respond to NRTIs. ${ }^{39}$ Triple therapy with efavirenz conferred greater and more durable viral suppression than triple therapy with nelfinavir. Two other trials compared protease inhibitor based and nevirapine based regimens in NRTI naive patients. ${ }^{40}$ In contrast to our findings, these trials showed similar degrees of viral suppression between the two drug classes. However, the characteristics of the patient populations in these two studies were different from those included in our meta-analysis: in addition to being NRTI naive, most patients had asymptomatic HIV infection and CD4 cell counts above 200 cells/ $\mu \mathrm{l}$. In the study comparing a nevirapine based and indinavir based triple regimen, patients in the nevirapine arm experienced a smaller increase in the absolute number of CD4 cells. ${ }^{41}$

\section{Implications and further research}

Our results provide important information for clinical practice, and may be especially relevant for physicians working in 


\section{What is already known on this topic}

Randomised clinical trials have strongly supported triple antiretroviral regimens in HIV infected patients

No trials have compared the clinical effectiveness of protease inhibitor regimens with non-nucleoside reverse transcriptase inhibitor (NNRTI) regimens

In the absence of such trials, indirect comparisons can provide useful information

\section{What this study adds}

Indirect comparisons suggest that triple regimens with protease inhibitors are superior to those with the NNRTIs nevirapine or delavirdine in patients with advanced disease who have used nucleoside reverse transcriptase inhibitors

In the absence of large trials directly comparing these regimens these results are relevant to current antiretroviral therapy, particularly in settings where resistance testing is not widely available

countries where resistance testing is not generally available. In these countries, patients tend to be at an advanced stage when starting therapy and, particularly in urban settings, a proportion will have been exposed to NRTI monotherapy or dual therapy. ${ }^{42}$ Large randomised experiments that directly compared protease inhibitor based and NNRTI based regimens and were powered to assess clinical end points could refute or confirm our findings, but such trials are unlikely to be performed. Our data thus make an important contribution to the best available evidence on the clinical effectiveness of triple regimens based in patients with immunodeficiency who have used NRTIs.

Contributors: GC had the idea for the review and ME proposed the indirect comparisons. YY, DS, YM, and GC initiated the review and designed the original protocol. DS was responsible for data collection under the supervision of YY and GC. DS, YY, and MZ performed the statistical analyses under the supervision of ME. YY together with ME and GC wrote the first draft of the paper. All authors contributed to the final version. YY will act as guarantor for the paper.

Funding: None.

Competing interests: YY has received travel grants from various pharmaceutical companies including Aventis, Boehringer Ingelhem, Bristol-Myers Squibb, Gilead Sciences, GlaxoSmithKline, Pfizer, Roche, and Schering Plough. He has received honorariums for presentation at workshops and consultancy honorariums from Boehringer Ingelheim, Bristol-Myers Squibb, GlaxoSmithKline, and Pfizer. ME has received travel grants, grants, or honorariums from Boehringer Ingelheim, Bristol-MyersSquibb, and GlaxoSmithKline. YM has received travel grants, grants, or honorariums from Abbott, Aventis, Boehringer Ingelheim, Bristol-Myers Squibb, Gilead Sciences, GlaxoSmithKline, Merck Sharp and Dohme, Pfizer, Roche, and Schering. GC has received consultancy honorariums from Aventis, Bristol-Myers Squibb, Gilead Sciences, GlaxoSmithKline, and Roche.

Ethical approval: None required.

1 Mocroft A, Vella S, Benfield TL, Chiesi A, Miller V, Gargalianos P, et al. Changing pat terns of mortality across Europe in patients infected with HIV-1. EuroSIDA Study Group. Lancet 1998;352:1725-30.

2 Palella FJ Jr, Delaney KM, Moorman AC, Loveless MO, Fuhrer J, Satten GA, et al. Declining morbidity and mortality among patients with advanced human immunodeficiency virus infection. HIV Outpatient Study Investigators. N Engl J Med 1998:338:853-60.

3 Egger M, Hirschel B, Francioli P, Sudre P, Wirz M, Flepp M, et al. Impact of new antiretroviral combination therapies in HIV infected patients in Switzerland: prospective multicentre study. Swiss HIV cohort study. BMJ 1997:315:1194-9.

4 Staszewski S, Morales-Ramirez J, Tashima KT, Rachlis A, Skiest D, Stanford J, et al. Efavirenz plus zidovudine and lamivudine, efavirenz plus indinavir, and indinavir plus zidovudine and lamivudine in the treatment of HIV-1 infection in adults. Study 006 Team. N Engl J Med 1999;341:1865-73.

5 Walmsley S, Bernstein B, King M, Arribas J, Beall G, Ruane P, et al. Lopinavir-ritonavir versus nelfinavir for the initial treatment of HIV infection. $N$ Engl J Med 2002;346:2039-46.

6 Fellay J, Boubaker K, Ledergerber B, Bernasconi E, Furrer H, Battegay M, et al. Prevalence of adverse events associated with potent antiretroviral treatment: Swiss HIV cohort study. Lancet 2001;358:1322-7.

7 Trotta MP, Ammassari A, Cozzi-Lepri A, Zaccarelli M, Castelli F, Narciso P, et al. Adherence to highly active antiretroviral therapy is better in patients receiving non-nucleoside reverse transcriptase inhibitor-containing regimens than in those non-nucleoside reverse transcriptase inhibitor-containing regimens than
receiving protease inhibitor-containing regimens. AIDS 2003;17:1099-102.

8 Human immunodeficiency virus type 1 RNA level and CD4 count as prognostic markers and surrogate end points: a meta-analysis. HIV Surrogate Marker Collaborative Group. AIDS Res Hum Retroviruses 2000;16:1123-33.

9 Bucher HC, Guyatt GH, Cook DJ, Holbrook A, McAlister FA. Users' guides to the medical literature: XIX. Applying clinical trial results. A. How to use an article measuring the effect of an intervention on surrogate end points. Evidence-Based Medicine Working Group. JAMA 1999;282:771-8.

10 Song F, Altman DG, Glenny AM, Deeks JJ. Validity of indirect comparison for estimating efficacy of competing interventions: empirical evidence from published meta-analyses. BMJ 2003;326:472.

11 Lefebvre C, Clarke M. Identifying randomised trials. In: Egger M, Smith G, Altman D, eds. Systematic reviews in health care:meta-analysis in context, 2nd ed. London: BMJ Books, 2001:69-86

12 Dybul M, Fauci AS, Bartlett JG, Kaplan JE, Pau AK. Guidelines for using antiretroviral agents among HIV-infected adults and adolescents. Ann Intern Med 2002;137:381-433.

13 Yeni PG, Hammer SM, Carpenter CC, Cooper DA, Fischl MA, Gatell JM, et al. Antiretroviral treatment for adult HIV infection in 2002: updated recommendations of the International AIDS Society-USA Panel. JAMA 2002;288:222-35.

14 Centers for Disease Control and Prevention. 1993 revised classification system for HIV infection and expanded surveillance case definition for AIDS among adolescents and adults. JAMA 1993;269:460.

15 Jüni P, Altman D, Egger M. Assessing the quality of controlled clinical trials. BMJ 2001;323:42-6.

16 Deeks J, Altman D, Bradburn M. Statistical methods for examining heterogeneity and combining results from several studies in meta-analysis. In: Egger M, Smith G, Altman D, eds. Systematic reviews in health care: meta-analysis in context, 2nd ed. London: BMJ Books, 2001:285-312

17 Thompson S, Sharp S. Explaining heterogeneity in meta-analysis: a comparison of methods. Stat Med 1999;18:2693-708.

18 Egger M, Smith G, Schneider M, Minder C. Bias in meta-analysis detected by a simple, graphical test. BMJ 1997;315:629-34

19 Sterne J, Egger M, Smith G. Investigating and dealing with publication and other biases in meta-analysis. BMJ 2001:323:101-5

20 Gulick RM, Mellors JW, Havlir D, Eron JJ, Gonzalez C, McMahon D, et al. Treatment with indinavir, zidovudine, and lamivudine in adults with human immunodeficiency virus infection and prior antiretroviral therapy. N Engl J Med 1997;337:734-9.

21 Hammer SM, Squires KE, Hughes MD, Grimes JM, Demeter LM, Currier JS, et al. A controlled trial of two nucleoside analogues plus indinavir in persons with human immunodeficiency virus infection and CD4 cell counts of 200 per cubic millimeter or less. AIDS Clinical Trials Group 320 Study Team. N Engl J Med 1997;337:725-33.

22 Cameron DW, Heath-Chiozzi M, Danner S, Cohen C, Kravcik S, Maurath C, et al. Randomised placebo-controlled trial of ritonavir in advanced HIV-1 disease. The Advanced HIV Disease Ritonavir Study Group. Lancet 1998;351:543-9.

23 D'Aquila RT, Hughes MD, Johnson VA, Fischl MA, Sommadossi JP, Liou SH, et al. Nevirapine, zidovudine, and didanosine compared with zidovudine and didanosine in patients with HIV-1 infection. A randomized, double-blind, placebo-controlled trial. National Institute of Allergy and Infectious Diseases AIDS Clinical Trials Group Protocol 241 Investigators. Ann Intern Med 1996;124:1019-30.

24 Collier AC, Coombs RW, Schoenfeld DA, Bassett RL, Timpone J, Baruch A, et al. Treatment of human immunodeficiency virus infection with saquinavir, zidovudine, and zalcitabine. AIDS Clinical Trials Group. N Engl J Med 1996;334:1011-7.

25 Henry K, Erice A, Tierney C, Balfour HH Jr, Fischl MA, Kmack A, et al. A randomized, controlled, double-blind study comparing the survival benefit of four different reverse transcriptase inhibitor therapies (three-drug, two-drug, and alternating drug) for the transcriptase inhibitor therapies (three-drug, two-drug, and alternating drug) for the
treatment of advanced AIDS. AIDS Clinical Trial Group 193A Study Team. J Acquir treatment of advanced AIDS. AIDS Clinical Trial

26 Montaner JS, Reiss P, Cooper D, Vella S, Harris M, Conway B, et al. A randomized, double-blind trial comparing combinations of nevirapine, didanosine, and zidovudine for HIV-infected patients: the INCAS Trial. Italy, The Netherlands, Canada and Australia Study. JAMA 1998;279:930-7.

27 Hirsch M, Steigbigel R, Staszewski S, Mellors J, Scerpella E, Hirschel B, et al. A randomized, controlled trial of indinavir, zidovudine, and lamivudine in adults with advanced human immunodeficiency virus type 1 infection and prior antiretroviral therapy. Infect Dis 1999;180:659-65.

28 Garcia F, Romeu J, Grau I, Sambeat MA, Dalmau D, Knobel H, et al. A randomized study comparing triple versus double antiretroviral therapy or no treatment in HIV-1infected patients in very early stage disease: the Spanish Earth-1 study. AIDS infected patients
$1999: 13: 2377-88$

29 Floridia M, Bucciardini R, Ricciardulli D, Fragola V, Pirillo MF, Weimer LE, et al. A randomized, double-blind trial on the use of a triple combination including nevirapine, a nonnucleoside reverse transcriptase HIV inhibitor, in antiretroviral-naive patients with advanced disease. J Acquir Immune Defic Syndr Hum Retrovirol 1999;20:11-9.

30 Friedland GH, Pollard R, Griffith B, Hughes M, Morse G, Bassett R, et al. Efficacy and safety of delavirdine mesylate with zidovudine and didanosine compared with two-drug combinations of these agents in persons with HIV disease with CD4 counts of 100 to 500 cells/mm3 (ACTG 261). ACTG 261 Team. J Acquir Immune Defic Syndr of 1009 to 500 cell: $281-92$

31 Stellbrink HJ, Hawkins DA, Clumeck N, Cooper DA, Myers R, Delfraissy JF, et al. Randomised, multicenter phase III study of saquinavir plus zidovudine plus zalcitabine in previously untreated or minimally pretreated HIV-infected patients. Clin Drug Invest 2000;20:295-307. 
32 Green S, Para MF, Daly PW, et al. Interim analysis of plasma viral burden reductions and CD4 increases in HIV-1-infected patients with rescriptor, retrovir, and epivir. 12th World AIDS conference, Geneva, 1998

33 Moyle G, de Cian W, Hawkins D, Wood R, Horban A, White D. Final 54-week analysi of a placebo-controlled trial (13 C) of delavirdine plus two nucleoside analogs (NA) versus two NA in drug-naive and experienced individuals. 39th interscience conference on antimicrobial agents chemotherapy, San Francisco, CA, 26-9 Sept 1999.

34 Cozzi-Lepri A, Phillips AN, d'Arminio Monforte A, Piersantelli N, Orani A, Petrosillo $\mathrm{N}$, et al. Virologic and immunologic response to regimens containing nevirapine or efavirenz in combination with 2 nucleoside analogues in the Italian Cohort Naive Antiretrovirals (I.Co.N.A.) study.J Infect Dis 2002;185:1062-9.

35 Matthews GV, Sabin CA, Mandalia S, Lampe F, Phillips AN, Nelson MR, et al. Virological suppression at 6 months is related to choice of initial regimen in antiretroviral-naive patients: a cohort study. AIDS 2002;16:53-61.

36 Phillips AN, Pradier C, Lazzarin A, Clotet B, Goebel FD, Hermans P, et al. Viral load outcome of non-nucleoside reverse transcriptase inhibitor regimens for 2203 mainly antiretroviral-experienced patients. AIDS 2001;15:2385-95

37 Van Leth F, Hassink E, Phanuphak P, Miller S, Gazzard B, Cahn P, et al. Results of the 2NN study: a randomized comparative trial of first-line antiretroviral therapy with regimens containing either nevirapine alone, efavirenz alone or both drugs combined, together with stavudine and lamivudine. 10th conference on retroviruses and opportunistic infections, Boston, MA, 10-14 Feb 2003.

38 Richman DD, Havlir D, Corbeil J, Looney D, Ignacio C, Spector SA, et al. Nevirapine resistance mutations of human immunodeficiency virus type 1 selected during therapy. J Virol 1994;68:1660-6.

39 Albrecht MA, Bosch RJ, Hammer SM, Liou SH, Kessler H, Para MF, et al. Nelfinavir, efavirenz, or both after the failure of nucleoside treatment of HIV infection. $N$ Engl Med 2001;345:398-407.
40 Podzamczer D, Ferrer E, Consiglio E, Gatell JM, Perez P, Perez JL, et al. A randomized clinical trial comparing nelfinavir or nevirapine associated to zidovudine/lamivudine in HIV-infected naive patients (the Combine Study). Antivir Ther 2002;7:81-90.

41 Van Leeuwen R, Katlama C, Murphy RL, Squires K, Gatell J, Horban A, et al. A randomized trial to study first-line combination therapy with or without a protease inhibitor in HIV-1-infected patients. AIDS 2003;17:987-999.

42 Weidle PJ, Malamba S, Mwebaze R, Sozi C, Rukundo G, Downing R, et al. Assessment of a pilot antiretroviral drug therapy programme in Uganda: patients' response, survival, and drug resistance. Lancet 2002;360:34-40.

(Accepted 6 January 2004)

doi 10.1136/bmj.37995.435787.A6

Service Universitaire des Maladies Infectieuses et du Voyageur, Centre Hospitalie de Tourcoing, Faculté de Médecine de Lille, BP 619, F 59208 Tourcoing, France Yazdan Yazdanpanah senior doctor of infectious disease

Daouda Sissoko doctor of infectious disease

Yves Mouton professor of infectious disease

Department of Social Medicine, University of Bristol,

Matthias Egger professor of clinical epidemiology

Department of Social and Preventive Medicine, University of Bern, Switzerland Marcel Zwahlen senior epidemiologist

INSERM U593, Bordeaux, France

Geneviève Chêne professor of clinical epidemiology

Correspondence to: $Y$ Yazdanpanah

yyazdan@yahoo.com 